\title{
Erratum
}

\section{SPRING FEN VEgETATION AND WATER CHEMISTRY IN THE WESTERN CARPATHIAN FLYSCH ZONE}

\section{Michal Hájek $^{1)}$, Petr Hekera ${ }^{2)}$ \& Petra Hájková ${ }^{1)}$}

1) Department of Botany, Faculty of Science, Masaryk University, Kotlársksá 2, CZ-611 37 Brno, Czech Republic; e-mail hajek@sci.muni.cz

2) Department of Ecology, Faculty of Science, Palacký University, Svobody 26, CZ-77I 46 Olomouc, Czech Republic; e-mail hekera@prfholnt.upol.cz

This paper was published in Folia Geobotanica 37: 205-224, 2002

The correct version of Fig. 1 is as follows:

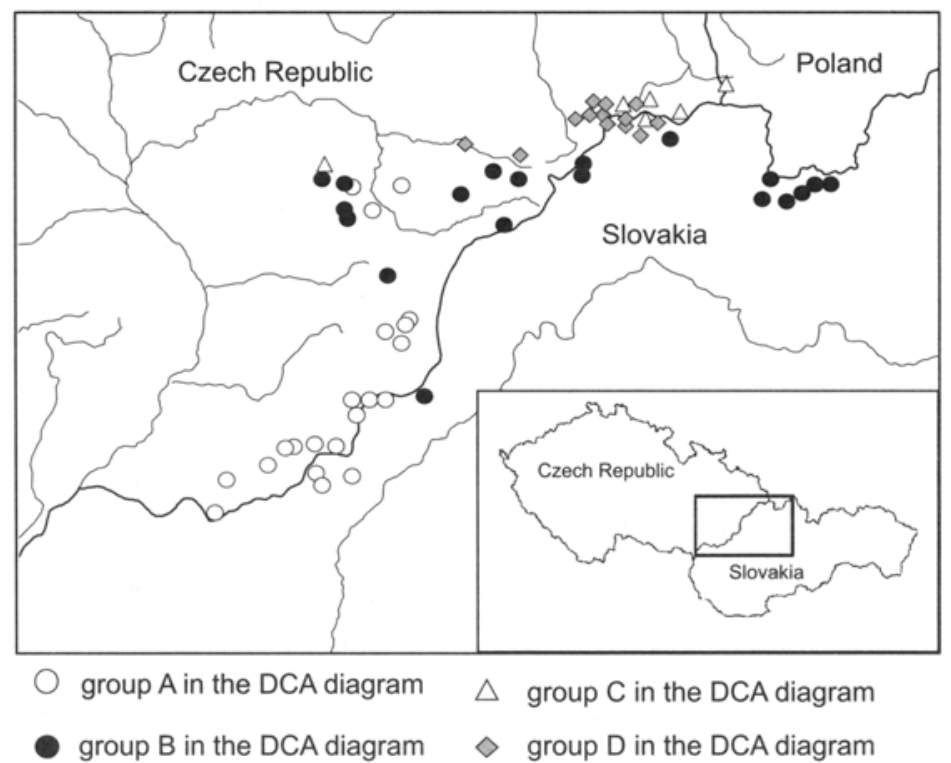

Fig. 1. The distribution of studied spring fens in the flysch borderland between the Czech Republic and Slovakia. For further explanations see text and Fig. 2. 